\title{
Sarcoma sinovial do antebraço: relato de caso
}

Autores: Caroline Marques de Aquino ${ }^{1 *}$, Marina Guarnieri ${ }^{1}$, Luana Rodrigues Maurício ${ }^{1}$ Orientador(a): Dra. Regina Yumi Saito ${ }^{2}$

${ }^{1}$ Universidade Nove de Julho, Curso de Medicina - São Paulo - SP

${ }^{2}$ Universidade Nove de Julho, Curso de Medicina - São Paulo - SP

*Autor correspondente: coralmarques99@gmail.com

\section{RESUMO}

Introdução: O sarcoma de partes moles é um subtipo raro de neoplasia que ocorre mais frequentemente nas extremidades. Dentre os subtipos histológicos está o sarcoma sinovial (SS). Este, afeta majoritariamente a população na terceira década de vida. Métodos: Para a confecção do presente relato, foram levantadas informações a partir da revisão do prontuário, entrevista com a paciente, registros fotográficos, além de uma busca nas bases de dados PubMed, (U.S. National Institute of Health) e Medline (Medical Literature Analysis and Retrievel System Online) usando os seguintes descritores: 'synovial sarcoma"' e "forearm". Descrição do caso: Feminino, branca, 17 anos, procurou o hospital oncológico com queixa de dor no antebraço direito desde os quatro anos de idade e nódulo local notado há três anos. Após a realização de exames de imagem e uma biópsia foi confirmado o diagnóstico de SS bifásico localizado no antebraço direito, sem metástases ou linfadenomegalias. O tratamento consistiu em ciclos de quimioterapia pré cirurgia, para a diminuição do tumor, seguida da cirurgia de ressecção tumoral e reconstrução com uma prótese metálica nos ossos, radioterapia e quimioterapia pós cirurgia. Confirmados os exames positivos da alta hospitalar, a paciente evoluiu bem, sem recidivas, e mantém apenas a avaliação semestral com o ortopedista e anual com o oncologista. Discussão: A manifestação clínica mais comum nos casos de SS é o surgimento de uma massa palpável, que pode ou não ser dolorosa e associada à limitação de mobilidade. Os tumores podem evoluir com metástases, frequentemente identificadas nos pulmões e nos linfonodos. $\mathrm{O}$ prognóstico nos casos de SS é, no geral, desfavorável, uma vez que boa parte dos pacientes apresenta recidivas locais, distantes ou evoluem para óbito. O tratamento dessa neoplasia envolve ressecção cirúrgica, quimioterapia e radioterapia adjuvante. O presente relato narra uma neoplasia pouco reportada na literatura, que ressalta a importância de uma investigação e entendimento adequados dessa doença pela comunidade médica. Considerações finais: $\mathrm{O}$ caso mencionado, em conjunto com os estudos levantados, auxiliam os profissionais da saúde a conhecerem melhor essa neoplasia rara e possibilitam diagnósticos e intervenções precoces. 
Palavras-chave: synovial sarcoma; forearm.

\section{INTRODUÇÃO}

O sarcoma de partes moles é um subtipo raro de neoplasia que pode ocorrer em qualquer parte do corpo, a maioria localizado nas extremidades. Histologicamente já foram identificados vários tipos de sarcoma, dentre eles o SS.

Essa neoplasia rara representa aproximadamente cinco a 10\% dos tumores de tecidos moles. Apesar de a maior parte dos casos conhecidos ocorrerem na terceira década de vida, o SS pode se desenvolver em qualquer idade.

O presente relato expõe o caso de uma adolescente de 17 anos com um SS no antebraço direito, tratado com ressecção cirúrgica combinada com radioterapia e quimioterapia adjuvante.

\section{MÉTODOS}

Para a confecção desse trabalho, foram levantadas informações a partir da revisão do prontuário, entrevista com a paciente e registros fotográficos. Além disso, foi realizada uma buscar nas bases de dados PubMed, (U.S. National Institute of Health) e Medline (Medical Literature Analysis and Retrievel System Online) usando os seguintes descritores: 'synovial sarcoma" e "forearm".

\section{DESCRIÇÃO DO CASO}

\section{Anamnese}

Paciente do sexo feminino, branca, 17 anos, procurou o hospital oncológico após consulta com ortopedista e encaminhamento, com queixa de dor no antebraço direito desde os quatro anos de idade e nódulo palpável notado há três anos, de evolução e crescimento lento há um ano.

\section{Exame físico}

No exame físico, a paciente encontrava-se em bom estado geral, com uma massa palpável e dolorosa no dorso do antebraço direito, porção média, imóvel, sem alterações na cor da pele e limites bem definidos à palpação. Os pulsos eram palpáveis e a paciente não apresentava restrições de mobilidade. 


\section{Exames complementares}

Os dados histológicos do terço médio do antebraço direito mostraram um processo expansivo de linhagem mista, comprometendo a musculatura extensora posterior do antebraço com invasão de membrana interóssea e acometimento de músculo flexor profundo dos dedos, bem como o envolvimento neurovascular interósseo.

A ressonância magnética evidenciou hipersinal nas sequências de imagens em T2 e isossinal à musculatura nas imagens em T1, com realce difuso e acentuado após a administração intravenosa do contraste paramagnético.

Cintilografia óssea revelou lesão hipervascularizada de partes moles com envolvimentos ósseos de rádio e ulna, localizada e sem metástases à distância. A biópsia confirmou a hipótese diagnóstica de SS bifásico (Figuras 1 e 2).

A Ultrassonografia da axila direita demonstrou pele e espessura normais sem linfonodomegalias axilares. A Ultrassonografia Doppler comprovou que não haviam áreas de fluxo anormal.

Nos demais exames subsidiários, as tomografias computadorizadas de tórax, abdômen e Raio x de tórax confirmaram a ausência de metástases a distância, nem acometimento de linfonodos.

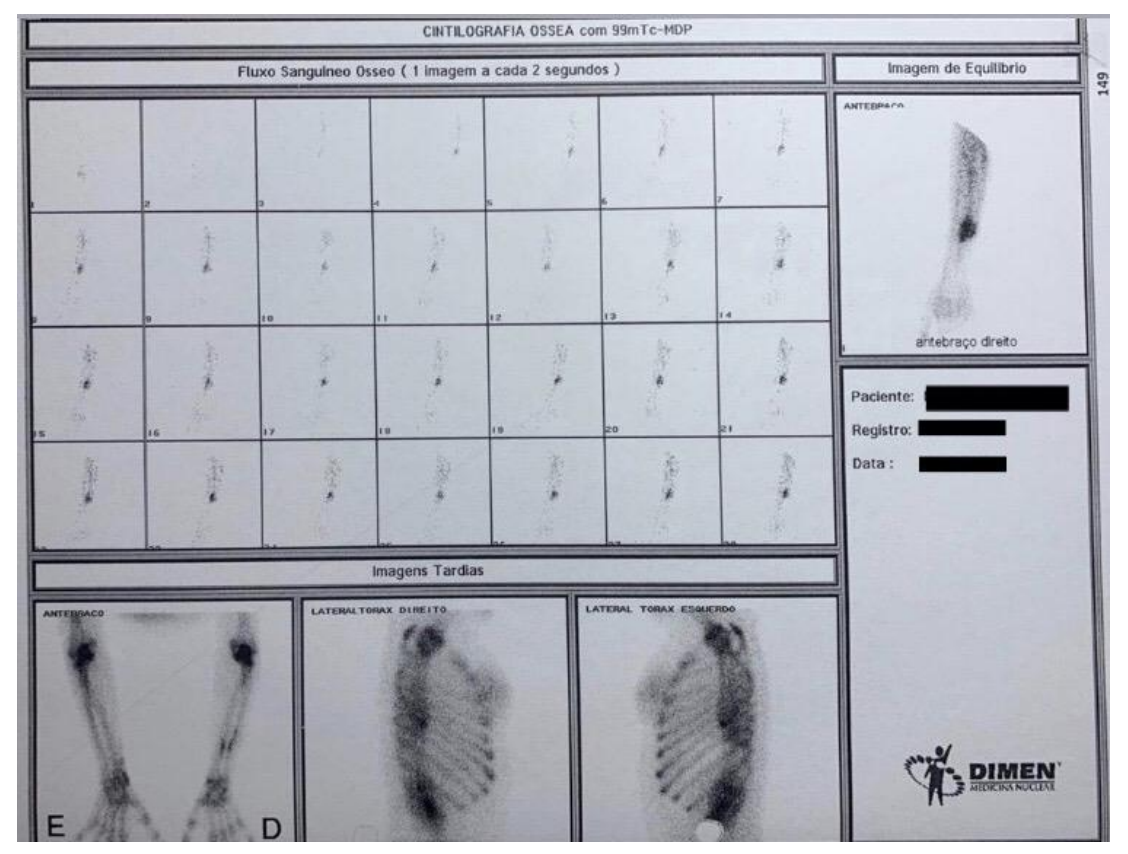




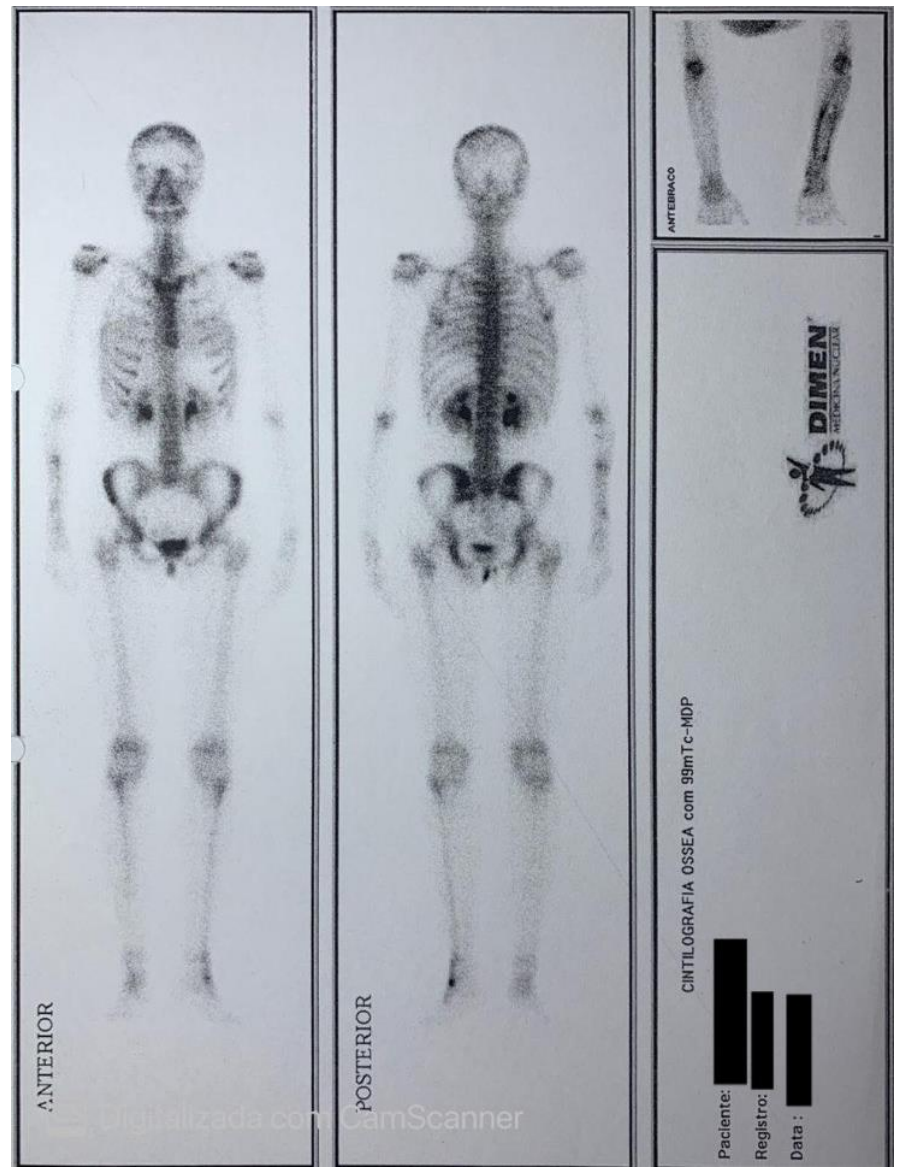

Figuras 1 e 2 - Cintilografia óssea de corpo total, com imagem de equilíbrio obtida na mesma projeção, demonstra fluxo sanguíneo aumentado para antebraço direito e moderado aumento da permeabilidade capilar no mesmo local.

\section{Conduta}

Após biópsia, confirmou-se a hipótese diagnóstica de SS bifásico. Assim, intervenção inicial consistiu em submeter a paciente a quatro ciclos de quimioterapia com intervalos de 28 dias por sessão. Esta conduta tinha como objetivo reduzir o tumor précirurgia.

\section{Conduta cirúrgica}

O plano inicial foi uma cirurgia de ressecção do bloco do SS e a reconstituição óssea com as fíbulas. Caso fosse constatada invasão tumoral de feixes vásculo-nervosos, haveria risco de amputação do membro. Contudo, ao realizar a incisão, notou-se que os nervos do plexo braquial e ramos da artéria braquial não estavam acometidos e a conduta foi substituída pela cirurgia de ressecção total do tumor e reconstrução dos ossos usando placas metálicas. 
A decisão do uso da prótese metálica ocorreu devido a estrutura óssea remanescente permitir a reconstrução sem a necessidade de utilização de enxerto autólogo. No entanto, o procedimento ocasionou a perda da musculatura extensora dos dedos.

\section{Evolução}

Pós cirurgia foi realizado o controle radiográfico do antebraço direito com 14 dias de diferença entre eles. Ambos mostraram ressecção das partes moles com perda de substância muscular no local da cirurgia (Figura 3).

A paciente também foi tratada com radioterapia adjuvante (Figura 4), recebeu 4500 cGy em 25 frações de 180 cGy em leito e margens, com reforço até 5400 cGy em leito cirúrgico. Uma fração ao dia, cinco dias por semana por um período de 49 dias úteis para controle local. Usou-se da técnica conformacional em acelerador linear de seis MV. Além disso, a paciente continuou a quimioterapia por mais 14 sessões.

Essa conduta pós-cirúrgica foi decidida em decorrência do que mostrou o laudo anatomopatológico do produto da ressecção tumoral. Este, revelou $60 \%$ de células tumorais viáveis com margens cirúrgicas livres pós-quimioterapia, porcentagem considerada elevada.

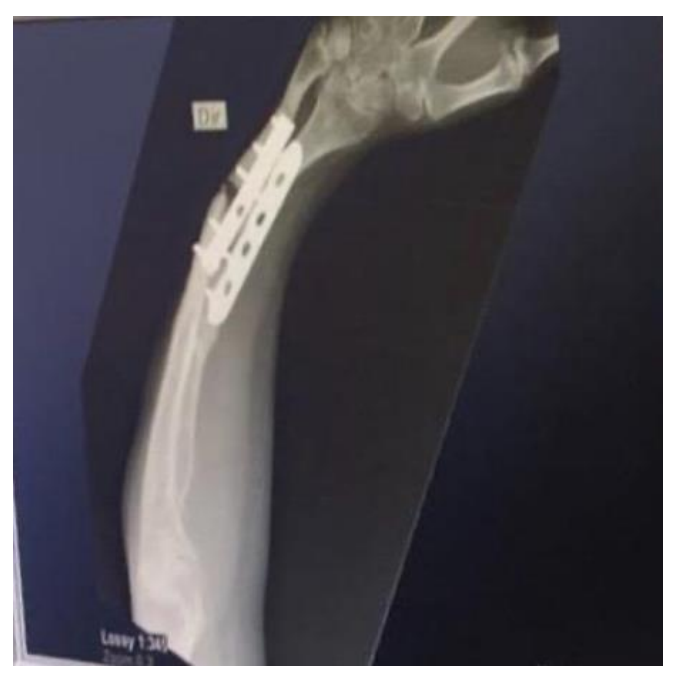

Figura 3 - Estudo radiográfico do antebraço direito pós cirurgia evidenciou as placas de suporte no rádio e na ulna no segmento médio diafisário. 


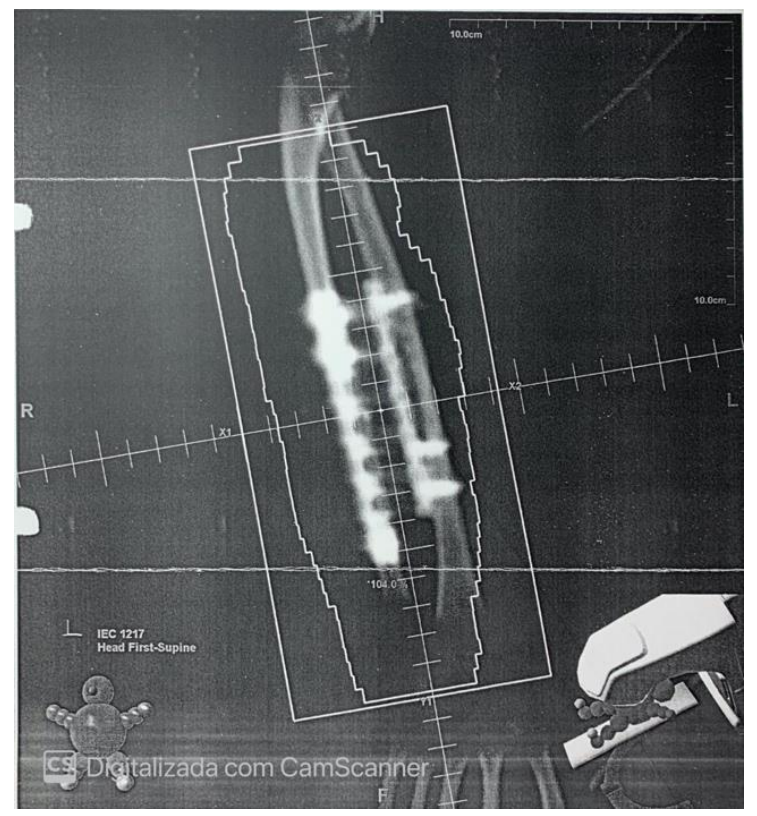

Figura 4 - Radioterapia guiada por imagem evidenciando o local do tratamento.

\section{Prognóstico e acompanhamento}

Pós alta hospitalar, a paciente evoluiu bem e encontra-se há 10 anos fora de tratamento e sem recidivas. Foi mantido o acompanhamento anual com a oncologia e o acompanhamento semestral com a ortopedia (Figura 5, 6 e 7).
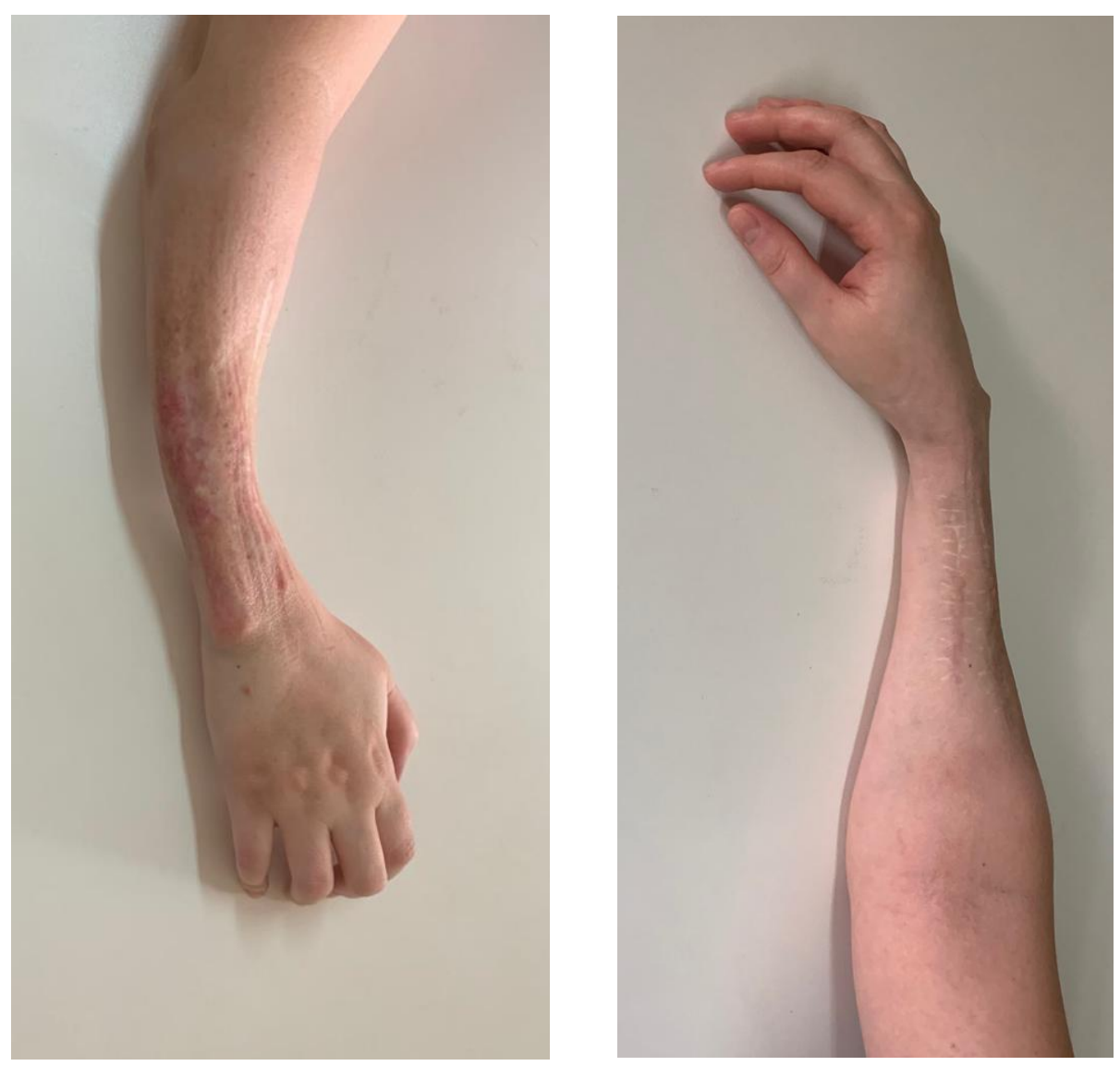
Figura 5 - Parte posterior do antebraço pós recuperação. Destaca a arqueação lateral do membro.
Figura 6 - Parte medial do antebraço. Evidencia a perda da musculatura extensora dos dedos.

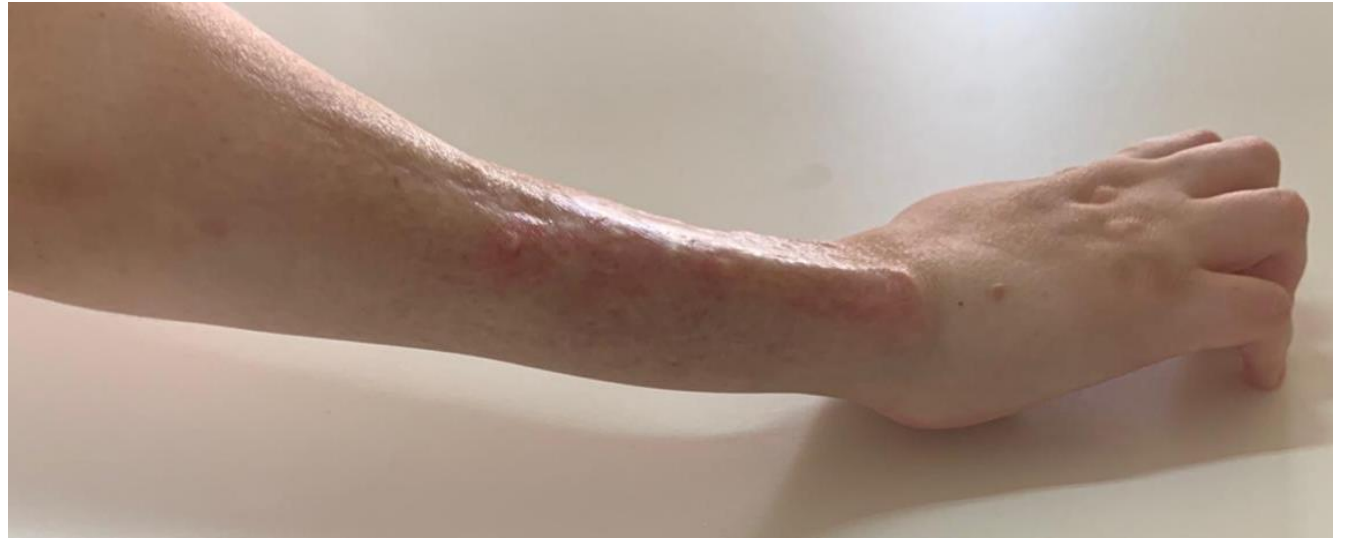

Figuras 7 - Parte lateral do antebraço. Exibe a hiperemia da pele devido a radioterapia.

\section{DISCUSSÃO}

O SS tem diferentes perfis histológicos. Por esse motivo, são divididos em dois subtipos: monofásico, de células mesenquimais em formato fusiforme, e bifásico, tanto células mesenquimais, como de células epiteliais glandulares.

As manifestações clínicas dessa neoplasia nem sempre são explícitas nos estágios iniciais da doença, o que torna seu diagnóstico precoce mais difícil. No entanto, as apresentações clínicas mais comuns incluem uma massa palpável, que pode ou não ser dolorosa e ser associada à limitação de mobilidade.

Uma vez diagnosticada, essa neoplasia, no geral, manifesta-se de forma agressiva, com ou sem a formação de metástases, mais frequentemente se localizam nos pulmões ou linfonodos ${ }^{2}$. O prognóstico do SS também é desfavorável em grande parte dos casos. Segundo o estudo conduzido por Lewis et al. (2000) abrangendo 112 pacientes que foram acompanhados durante uma média de 72 meses, houve recidiva local em 12\%, recidiva distante em $39 \%$ e mortalidade em $25 \%$ dos envolvidos após 5 anos da ressecção cirúrgica do primeiro tumor. Essa pesquisa também concluiu que o tamanho do sarcoma e a invasão de estruturas ósseas e neurovasculares são dados indispensáveis para determinar o curso dessa neoplasia.

O tratamento do SS pode envolver a ressecção cirúrgica, e ainda ser combinado com radioterapia e quimioterapia.

O caso reportado no presente estudo apresenta uma paciente cuja neoplasia envolveu ambos os ossos do antebraço (rádio e ulna), sem agredir estruturas mais profundas ou nervosas, o que possibilitou uma abordagem cirúrgica que não envolvesse 
a amputação do membro e com sequelas mínimas. Um caso pouco discutido na literatura e que ressalta a importância de uma investigação e entendimento adequados dessa doença pela comunidade médica.

\section{CONSIDERAÇÕES FINAIS}

O SS, além de pouco conhecido, é de difícil diagnóstico. Por isso, o caso apresentado e as publicações analisadas auxiliam o processo de entendimento dessa neoplasia rara e facilitam o diagnóstico precoce dessa doença. Assim, as intervenções podem ser feitas antes do crescimento agressivo do tumor, ou das metástases, fatores determinantes para o bom prognóstico dos pacientes.

\section{REFERÊNCIAS BIBLIOGRÁFICAS}

Cormier, JN; Pollock, RE. Soft Tissue Sarcomas. CA Cancer J Clin, v. 54, p. 94-109, 2004.

Vlenterie, M; Jones, RL; van der Graaf, WT. Synovial sarcoma diagnosis and management in era of targeted therapies. Curr Opin Oncol, v. 27, p. 316-322, 2015.

Stacchiotti S; Van Tine, BA. Synovial Sarcoma: Current Conceps and Future Perspectives. J Clin Oncol, v. 26, p. 180-187, 2018. 